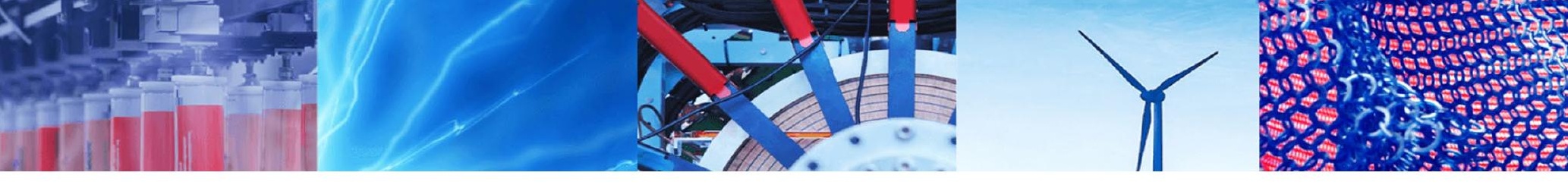

Research Article

\title{
Preparation and evaluation of aceclofenac dental pastes using dillenia fruit gum for periodontitis treatment
}

\author{
Md. Saquib Hasnain ${ }^{1}\left[\right.$ Poonam Rishishwar ${ }^{1} \cdot$ Sadath Ali $^{2} \cdot$ Amit Kumar Nayak ${ }^{3}$
}

Received: 21 November 2019 / Accepted: 12 February 2020 / Published online: 17 February 2020

(c) Springer Nature Switzerland AG 2020

\begin{abstract}
The present research deals with preparation and evaluation of aceclofenac dental pastes containing extracted dillenia fruit gum (DG) for periodontitis treatment. Dental pastes containing $1 \% \mathrm{w} / \mathrm{w}$ aceclofeanc were prepared with/without using extracted DG as a mucoadhesive polymer via conventional trituration method. The drug contents, viscosities and $\mathrm{pHs}$ of these dental pastes were observed within the permissible ranges. The tube extrudability and tube spreadability of these pastes containing extracted DG were found favorable. The in vitro aceclofenac release from all these dental pastes was found slower sustained over $6 \mathrm{~h}$, which followed zero-order kinetic model $\left(R^{2}=0.9917-0.9988\right)$ with super case-II transport mechanism $(n=1.00-1.03)$. The in vitro aceclofenac release was found decreased with the viscosity increment of these dental pastes. These aceclofenac dental pastes containing extracted DG demonstrated excellent mucoadhesion onto excised porcine buccal mucosal membrane, which can be beneficial to get intimate contact with the action site during and after application to uphold the constant release of drugs over prolonged time. These dental pastes containing $1 \% \mathrm{w} / \mathrm{w}$ aceclofeanc can be applied for effective management of dental pain and inflammation with local delivery in the treatment of periodontitis.
\end{abstract}

Keywords Dillenia fruit gum · Dental pastes · Drug release $\cdot$ Aceclofenac

\section{Introduction}

Periodontitis is an oral disease [1, 2]. The early phase of periodontitis leads to a painful agony related to inflammation and bleeding of gums [3]. The untreated periodontitis can damage both hard as well as soft tissues of the teeth that eventually may be advanced to the tooth loss $[4,5]$. The current treatment of periodontitis includes the systemic deliveries of anti-inflammatory drugs to reduce pain and inflammation along with antibiotics to eradicate the microorganisms from the diseased periodontal site over a prolonged period [5]. The systemic deliveries of anti-inflammatory drugs and antibiotics are often experience systemic side effects of drugs because of the long term use [6]. The local drug deliveries are recently being researched for the treatment of periodontitis to decrease the side effects of drugs, which are familiar with the treatment by delivering drugs via the systemic route $[7,8]$. The current periodontitis research and discoveries have explained that the prostaglandin production inhibitors like non-steroidal anti-inflammatory drugs (NSAIDs) may possibly influence the course of hard tissue loss of the teeth in periodontitis $[8,9]$. Even several periodontitis research findings already indicated that NSAIDs able to lessen the gingival inflammation and the alveolar bone resorption [10]. The efficacy of medicated dental pastes for topical deliveries of drugs have been established more reasonably priced towards the patient's preference as well as the

$\triangle$ Md. Saquib Hasnain, msaquibhasnain@gmail.com; $\square$ Amit Kumar Nayak, amitkrnayak@yahoo.co.in| ${ }^{1}$ Department of Pharmacy, Shri Venkateshwara University, NH-24, Rajabpur, Gajraula, Amroha, UP 244236, India. ${ }^{2}$ Department of Pharmacy, Glocal University, Saharanpur, UP 247001, India. ${ }^{3}$ Department of Pharmaceutics, Seemanta Institute of Pharmaceutical Sciences, Mayurbhanj, Odisha 757086, India. 
industrial point of view than other marketed formulations $[6,10,11]$. Nowadays, due to less toxicity and biodegradability, natural polymers are being extensively used for the formulation of various dosage forms [12-27]. Hence, in the current work, we attempted the preparation and evaluation of dental pastes of $1 \% \mathrm{w} / \mathrm{w}$ aceclofeanc prepared with/without using extracted dillenia fruit gum (DG) as a natural mucoadhesive polymer via the conventional trituration method.

Aceclofenac is a NSAID of acetic acid derivative category $[28,29]$. Chemically, it is $2-\left[\left(2^{\prime}, 6^{\prime}\right.\right.$-dichlorophenyl) amino] phenylacetoxyacetic acid [30]. It is widely used in the management of pain and inflammation [31, 32]. Aceclofenac is also reported to reduce the dental pain and inflammation [33]. DG is a plant derived polysaccharide extracted from mature and ripe dellinia (Dillenia indica L., family: Dilleniaceae) fruits [34]. It is a biocompatible and nontoxic in nature [35]. It is also soluble in cold water and hot water. DG is also reported as gelling material and mucoadhesive in various applications [33, 36]. During past few years, DG is being utilized as a potential pharmaceutical excipient material in different drug delivery systems like nasal mucoadhesive gels, sustained releasing tablets and microbeads [33-38]. The objective of the current work was to prepare dental pastes of $1 \% \mathrm{w} / \mathrm{w}$ aceclofeanc with/ without using extracted dillenia fruit gum (DG) as a natural mucoadhesive polymer via the conventional trituration method. These dental pastes were evaluated for drug content uniformity, $\mathrm{pH}$, viscosity, tube spreadability, tube extrudability, in vitro drug releasing and ex vivo biomucoadhesion onto the excised porcine buccal mucosal membrane.

\section{Materials and methods}

\subsection{Materials}

Aceclofeanc (B. S. Traders Pvt. Ltd., India), calcium carbonate (precipitated chalk, LobaChemie Pvt. Ltd., India), sodium lauryl sulfate (SD Fine Chemicals, India), potassium dihydrogen orthophosphate (SD Fine Chemicals, India), glycerine (Loba Chemie Pvt. Ltd., India), methyl paraben (SD Fine Chemicals, India), camphor (Qualigens Fine Chemicals, India), sodium hydroxide (SD Fine Chemicals, India), dialysis membrane (molecular cut off $10 \mathrm{~K} \mathrm{Da}$; Thermo Fisher Scientific India Pvt. Ltd., India) and empty aluminium collapsible tubes (Digvijay Containers \& Closures, India) were used. DG was extracted from mature and ripe dellinia fruits purchased from Baripada market (District: Mayurbhanj, Odisha) in the month of September, 2015. All other reagents and chemicals were of commercially available and analytical grade.

\subsection{Extraction of DG}

DG was extracted mature and ripe dillenia fruits as earlier reported methodology by Kuotsu and Bandyopadhyay (2007) with minute adjustments. Dillenia fruits were thoroughly cleaned using water and cut into small pieces by using a knife [33]. Pieces of dillenia fruits $(1 \mathrm{~kg})$ were soaked by the demineralized water and subsequently, these were boiled using an electric water bath at $45 \pm 1{ }^{\circ} \mathrm{C}$ under occasional stirring until thick slurry was appeared. The formed thick slurry was cooled and after that, it was kept in a laboratory refrigerator for a period of 1 day. The clear solution at the upper portion was shifted and afterward, centrifuged at the speed of $500 \mathrm{rpm}$ for a period of $20 \mathrm{~min}$. The clear supernatant was collected and concentrated using an electric water bath at $50 \pm 2{ }^{\circ} \mathrm{C}$ until the volume decrease to $1 / 4$ th of the starting volume. The concentrated solution was cooled down to the room temperature and then, poured into $1 / 3$ th volume of acetone with constant stirring using a magnetic stirrer (Remi Motors, India). The formed precipitate was washed repetitively with acetone and subsequently with demineralised water. The washed precipitate was separated and then, dried in an oven at $45 \pm 1{ }^{\circ} \mathrm{C}$ for $12 \mathrm{~h}$. The dried DG was crushed to fine powder using a pestle and mortar, passed through the 80 mesh screen and finally, stored in air tight desiccators.

\subsection{Preparation of dental pastes}

Conventional trituration method was employed for the preparation of $1 \% \mathrm{w} / \mathrm{w}$ aceclofenac dental pastes. In brief, extracted DG, methyl paraben and glycerine were blended together using clean mortar and pestle with half-quantity of water. Then, in remaining half quantity of water, $1 \% \mathrm{w} / \mathrm{w}$ of aceclofenac was dissolved and this mixture was added to the above mixture with continuous trituration for half an hour. Calcium carbonate was sieved by passing 75 sieve and added to the above mixture gradually. Then, camphor was mixed with this by means of continued mixing until the formation of smooth paste. The formulas of various $1 \% \mathrm{w} / \mathrm{w}$ aceclofenac dental pastes prepared with/without using extracted DG were given in Table 1.

\subsection{Determination of drug content uniformity}

The prepared aceclofenac dental pastes $(5 \mathrm{mg}$ ) were taken and then, dissolved in $100 \mathrm{ml}$ of demineralized water by magnetic stirrer-set (Remi Motors, India) for $30 \mathrm{~min}$ at $400 \mathrm{rpm}$ in room temperature. Then, mixture solution was filtered through Whitman filter paper. At the $274.5 \mathrm{~nm}$ wavelength $\left(\lambda_{\max }\right)$ against the appropriate 
Table 1 Formula of various 1\% w/w aceclofenac dental pastes containing extracted DG

\begin{tabular}{lllll}
\hline Codes & AD1 & AD2 & AD3 & AD \\
\hline Calcium carbonate (g) & 42.50 & 42.00 & 41.50 & 44.00 \\
Glycerine (g) & 28.00 & 28.00 & 28.00 & 28.00 \\
Isolated DG (g) & 1.50 & 2.00 & 2.50 & - \\
Methyl paraben (g) & 0.50 & 0.50 & 0.50 & 0.50 \\
Camphor (g) & 1.50 & 1.50 & 1.50 & 1.50 \\
Sodium lauryl sulfate (g) & 1.50 & 1.50 & 1.50 & 1.50 \\
Aceclofenac (\% w/w) & 1.00 & 1.00 & 1.00 & 1.00 \\
Water qs to 100 g & qs & qs & qs & qs \\
\hline
\end{tabular}

blank, the absorbances of filtrate samples were measured spectrophotometrically by means of UV-Vis Spectrophotometer (Shimadzu, Japan) to calculate the drug content uniformity.

\section{$2.5 \mathrm{pH}$ measurement}

In a $250 \mathrm{ml}$ clean beaker, $1 \mathrm{gm}$ of prepared aceclofenac dental pastes were taken and after that, $100 \mathrm{ml}$ of demineralised water was added each beaker containing pastes, separately at the room temperature. These mixture solutions were well stirred by magnetic stirrer-set (Remi Motors, India) for $30 \mathrm{~min}$ at $400 \mathrm{rpm}$ to make thorough suspensions for each tested dental pastes. With the help of digital pH meter (Systronics Instruments, India), $\mathrm{pHs}$ of the suspensions were measured within 5 min by introducing the glass electrode completely into these suspensions.

\subsection{Viscosity measurement}

With the help of a Brookfield viscometer (Brookfield DV III ultra V6.0 RV, MA), viscosities of these prepared aceclofenac dental pastes were measured at $25 \pm 0.3^{\circ} \mathrm{C}$. Calculations of viscosities were done by employing Rheocalc V2.6 software.

\subsection{Tube spreadability measurement}

Prepared aceclofenac dental pastes of $1 \mathrm{gm}$ were weighed at the centre of the glass-plate $(10 \mathrm{~cm} \times 10 \mathrm{~cm})$ and carefully positioned a new glass-plate over it. For each formulation of aceclofenac dental pastes, a weight of $2 \mathrm{~kg}$ was placed at the centre of the glass-plate (to avoid sliding of the glass-plate) and then, the diameters for each tested dental pastes were measured after $30 \mathrm{~min}$.

\subsection{Tube extrudability measurement}

To measure the tube extrudabilities, the prepared aceclofenac dental pastes were filled in clean lacquered aluminium collapsible tubes with a nasal tip (having $5 \mathrm{~mm}$ opening). Pressure was applied on these collapsible tubes containing dental pastes by pressing finger-tip. The tube extrudabilities were measured by assessing the percentage extruded amount of pastes through the tip as soon as the pressure was applied by pressing finger-tip on the collapsible tubes.

\subsection{In vitro drug release studies}

With the help of a permeation cell (a glass cylinder of $10 \mathrm{~cm}$ in height, $3.7 \mathrm{~cm}$ in the outer diameter and $3.1 \mathrm{~cm}$ in the inner diameter with both the ends open), release study of prepared aceclofenac dental pastes was done. A dialysis membrane (molecular cut off $10 \mathrm{~K} \mathrm{Da}$ ) was taken and was soaked distilled water for $24 \mathrm{~h}$ before use. The water-soaked dialysis membrane was then, attached to the last part of the cylinder with the help of a strong glue. Prepared dental paste of $1 \mathrm{~g}$ was placed in the permeation cell. A beaker containing phosphate buffer $(\mathrm{pH} 6.4)$ of $100 \mathrm{ml}$ was employed as the receptor compartment. Dental paste was dipped to a depth of below the surface of the receptor compartment medium. The receptor compartment medium was agitated by a magnetic stirrer (Remi Motors, India) maintained at temperature of $37 \pm 0.5^{\circ} \mathrm{C}$. $5 \mathrm{ml}$ of samples were withdrawn at regular time interval and then, the withdrawn samples were filtered through Whitman filter papers. Aceclofenac released from the dental pastes were assayed spectrophotometrically using UV-Vis spectrophotometer (Shimadzu, Japan) at $274.5 \mathrm{~nm}$ wavelength $\left(\lambda_{\max }\right)$ against the appropriate blank.

\subsection{Analysis of in vitro drug release kinetics and mechanism}

In vitro drug releasing from the dental pastes was analyzed by fitting with various kinetic models [39-41]:

Zero order model : $Q=k_{0} t+Q_{0}$

First order model : $Q=Q_{0} e^{k 1 t}$

Higuchi model : $Q=k_{H} t^{1 / 2}$

Korsmeyer - Peppas model : $Q=k_{K P} t^{n}$

$\mathrm{Q}$ and $\mathrm{Q}_{0}$ symbolize the amount of aceclofenac released at time, $\mathrm{t}$ and 0 , respectively; $\mathrm{k}_{0}, \mathrm{k}_{1}, \mathrm{k}_{\mathrm{H}}$ and $\mathrm{k}_{\mathrm{KP}}$ designate aceclofenac releasing rate constants. In addition, $\mathrm{n}$ represents the release exponent implying drug releasing mechanism 
$[42,43]$. When $\mathrm{n}$ is $\leq 0.5$, the Fickian diffusion (non-steady) mechanism controls. When $n$ is $\geq 1$, the case-Il transport (zero order) mechanism controls the drug release. When $\mathrm{n}$ is in-between 0.5 to 1 ; this refers to non-Fickian (anomalous) diffusion mechanism [39, 44-46].

\subsection{Ex vivo mucoadhesion studies}

\subsubsection{Preparation of porcine buccal mucosal membrane}

The porcine buccal mucosa was excised from the cheek pouch of pork (collected from the local slaughtering shop) as said by the earlier research by Ratha Adhikari et al. [47]. The porcine cheek pouch was collected within $1 \mathrm{~h}$ of after sacrificing the animal in slaughtering shop and then, brought to the laboratory within the phosphate buffer $(\mathrm{pH}$ 6.8), instantly. The mucosal membrane was disconnected from the full thickness of buccal mucosa layer and then, immersed in the phosphate buffer $(\mathrm{pH} \mathrm{6.8)}$ for $1 \mathrm{~min}$ at $37 \pm 0.5^{\circ} \mathrm{C}$. By using a scalpel, the fat layers present onto the buccal mucosal membrane were eliminated, and the buccal mucosal membrane was then separated. Finally, the collected excised buccal mucosal membrane was rinsed using phosphate buffer ( $\mathrm{pH} 6.8)$.

\subsubsection{Ex vivo biomucoadhesion measurement}

Ex vivo biomucoadhesion measurement of these formulated aceclofenac dental pastes were performed using excised porcine buccal mucosal membrane by the help of modified physical balance [48]. The excised porcine buccal mucosal membrane was fixed and attached to open mouth of glass vial containing phosphate buffer ( $\mathrm{pH}$ 6.8). The glass vial was fixed compactly at the centre of a beaker containing phosphate buffer ( $\mathrm{pH}$ 6.8). Aceclofenac dental pastes of $1 \mathrm{~g}$ of each sample were fixed to the lower part of rubber stopper. A preload initial pressure by finger tip was applied to set the tested dental paste sample and the excised porcine buccal mucosal membrane for $5 \mathrm{~min}$. The mass (in g) required to disconnect the lower-side of the rubber stopper from mucosal membrane surface was noted as mucoadhesive strength (shear stress). In addition, force of adhesion and bonding strength of these aceclofenac dental pastes were calculated using the following formula [47, 49]:

Force of adhesion $(\mathrm{N})=\frac{\text { Mucoadhesive strength } \times 9.81}{1000}$

\subsection{Statistical analysis}

All data was analyzed by the simple statistical analyses. Simple statistical analyses were performed by MedCalc software version 11.6.1.0.

\section{Results and discussion}

\subsection{Preparation of dental pastes}

In the present work, dental pastes of $1 \% \mathrm{w} / \mathrm{w}$ aceclofeanc were prepared for efficient dental pain and gum inflammation management in the treatment of periodontitis. These aceclofenac dental pastes were prepared with/without using extracted DG as a natural mucoadhesive plantderived polysaccharide via the conventional trituration method. In the formulas of aceclofenac $(1 \% \mathrm{w} / \mathrm{w})$ dental pastes containing extracted $D G$ as mucoadhesive polymer (AD1, AD2 and AD3), isolated DG was varied at three different concentrations with calcium carbonate (incorporated as abrasive agent) (Table 1). In all these medicated dental pastes, glycerine (as humectant and co-solvent), sodium lauryl sulphate (as surfactant), methyl paraben (as preservative) and camphor (as flavoring agent) were incorporated. The prepared dental pastes were observed white in colour and sticky in nature.

\subsection{Drug content}

The prepared aceclofenac $(1 \% \mathrm{w} / \mathrm{w})$ dental pastes exhibited the drug contents within the range, $95.95 \pm 3.28$ $99.03 \pm 4.75 \%$ (Table 2 ). These results also indicated the drug contents within these aceclofenac dental pastes prepared with/without using extracted DG as a natural mucoadhesive plant derived polysaccharide via conventional trituration method were within the acceptable range (>95\%) suggesting uniform mixing and distribution of drug (aceclofenac) with other excipients incorporated in the paste formula.

Table 2 Drug content (\%), $\mathrm{pH}$ and viscosity (cps) of various aceclofenac $(1 \% \mathrm{w} / \mathrm{w})$ dental pastes containing extracted DG

\begin{tabular}{llll}
\hline $\begin{array}{l}\text { Formulation } \\
\text { codes }\end{array}$ & $\mathrm{pH}$ & Drug content $(\%)^{\mathrm{a}}$ & Viscosity (cps) \\
\hline AD1 & 6.33 & $98.83 \pm 4.23$ & 59832.28 \\
AD2 & 6.15 & $96.38 \pm 3.67$ & 60274.03 \\
AD3 & 6.02 & $95.95 \pm 3.28$ & 64353.17 \\
AD & 6.72 & $99.03 \pm 4.75$ & 40050.28 \\
\hline
\end{tabular}

${ }^{\mathrm{a}}$ Mean \pm standard error, $\mathrm{n}=3$ 


\section{$3.3 \mathrm{pH}$}

The $\mathrm{pHs}$ of prepared aceclofenac $(1 \% \mathrm{w} / \mathrm{w})$ dental pastes were measured within the range, $6.02-6.72$ (Table 2). The result of $\mathrm{pH}$ indicated that these dental pastes were in proximity to the standard ranges of oral $\mathrm{pH}$, which should not produce any oral mucosal irritation upon application.

\subsection{Viscosity}

The viscosities of prepared aceclofenac ( $1 \% \mathrm{w} / \mathrm{w})$ dental pastes were evaluated using a Brookfield viscometer at room temperature. The viscosity of aceclofenac dental paste prepared without using extracted DG (AD) was measured as 40,050.28 cps; while viscosities of dental pastes prepared using isolated DG as natural mucoadhesive agent (AD1, AD2 and AD3) were within the range, 59,832.28-64,353.17 cps (Table 2). In these aceclofenac dental pastes, it was observed that the pastes formulated without using extracted DG (AD) was found less viscous; whereas, the pastes formulated with $2.50 \%$ of extracted DG (AD3) was found highly viscous $(64,353.17 \mathrm{cps})$ than that of the others.

\subsection{Tube spreadability}

The high-quality pastes should have higher spreadability that these take less time to spread all over the application area. To measure the spreadability of these newly prepared aceclofenac $(1 \% \mathrm{w} / \mathrm{w})$ dental pastes, tube spreadability test was done and it was observed that the tube spreadability of these dental pastes were within the range, $6.03 \pm 0.27-7.97 \pm 0.53 \mathrm{~cm}$ (Table 3 ). The aceclofenac dental paste prepared without using extracted DG (AD) showed better tube spreadability. As the concentration of extracted DG in the dental paste formula was increased, the tube spreadabilities of these dental pastes (AD1, AD2 and AD3) were found to be reduced. From the results of tube spreadability test, it was noticed that the less viscous

Table 3 Tube spreadability and tube extrudability of various aceclofenac $(1 \% \mathrm{w} / \mathrm{w})$ dental pastes containing extracted DG

\begin{tabular}{lll}
\hline $\begin{array}{l}\text { Formulation } \\
\text { codes }\end{array}$ & $\begin{array}{l}\text { Tube spreadability } \\
(\mathrm{cm})^{\mathrm{a}}\end{array}$ & Tube extrudability $(\%)^{\mathrm{a}}$ \\
\hline AD1 & $6.03 \pm 0.27$ & $90.38 \pm 3.52$ \\
AD2 & $6.11 \pm 0.35$ & $88.03 \pm 2.73$ \\
AD3 & $6.27 \pm 0.33$ & $83.88 \pm 3.27$ \\
AD & $7.97 \pm 0.53$ & $97.44 \pm 3.19$ \\
\hline
\end{tabular}

${ }^{\mathrm{a}}$ Mean \pm standard error, $\mathrm{n}=3$ pastes extrude from the tube with difficulty, whereas highly viscous pastes flow quickly.

\subsection{Tube extrudability}

The tube extrudability of these newly prepared aceclofenac $(1 \% \mathrm{w} / \mathrm{w})$ dental pastes were observed within the range of $83.88 \pm 3.27-83.88 \pm 3.27 \%$ (Table 3 ). As the concentration of extracted DG in the dental paste formula increased, tube extrudabilities of these dental pastes were found to be reduced. It was noticed that the pastes of high viscosity exhibited lower tube extrudability. The high-quality pastes should have higher tube extrudability, which is helpful for the easy removal of the pastes from the collapsible tubes at the time of application. Therefore, higher extrudability of paste from collapsible tube is important for the patient compliance.

\subsection{In vitro drug release}

In vitro drug releasing study of prepared aceclofenac $(1 \% \mathrm{w} / \mathrm{w})$ dental pastes prepared with/without using extracted DG as a natural mucoadhesive plant derived polysaccharide was done in phosphate buffer $(\mathrm{pH} 6.4)$. The in vitro aceclofenac release from all these dental pastes ( $A D, A D 1, A D 2$, and AD3) was observed to be slower sustained over $6 \mathrm{~h}$ (Fig. 1). As the concentration of extracted DG in the paste formula was increased, in vitro percent of cumulative aceclofenac releases from these prepared dental pastes was found decreased. This occurrence can be due to the augmented viscosities of pastes with increment of the concentration of extracted DG.

In vitro aceclofenac releasing from these prepared dental pastes was analyzed by fitting with various kinetic models. When individual correlation coefficients were evaluated by fitting with kinetic models, it was observed to follow zero-order kinetic model mainly with a correlation coefficient nearer to $1\left(R^{2}=0.9917-0.9988\right)$ in case of those dental pastes (AD1, AD2, and AD3) which contained isolated DG in the formula (Table 4). Moreover, Korsmeyer-Peppas model $\left(\mathrm{R}^{2}=0.9879-0.9937\right)$ was also observed to be nearer to the best-fitting zero-order model. Calculated values of release exponent ( $n$ ) of dental pastes prepared using extracted DG were reported as above $1(n=1.00-1.03)$ (Fig. 2), which suggested that the in vitro releasing of aceclofenac from these dental pastes followed the case-II transport mechanism. On the other hand, dental pastes prepared without extracted DG (AD) was observed to be best-fitting with the first-order kinetic model $\left(R^{2}=0.9902\right)$ and $n$ value of it was measured as 0.68 indicating the non-Fickian (anomalous) diffusion mechanism of drug releasing (Table 4; Fig. 2). 
Fig. 1 In vitro aceclofeanc release from various aceclofenac $(1 \% \mathrm{w} / \mathrm{w})$ dental pastes (mean \pm standard error, $\mathrm{n}=3)$

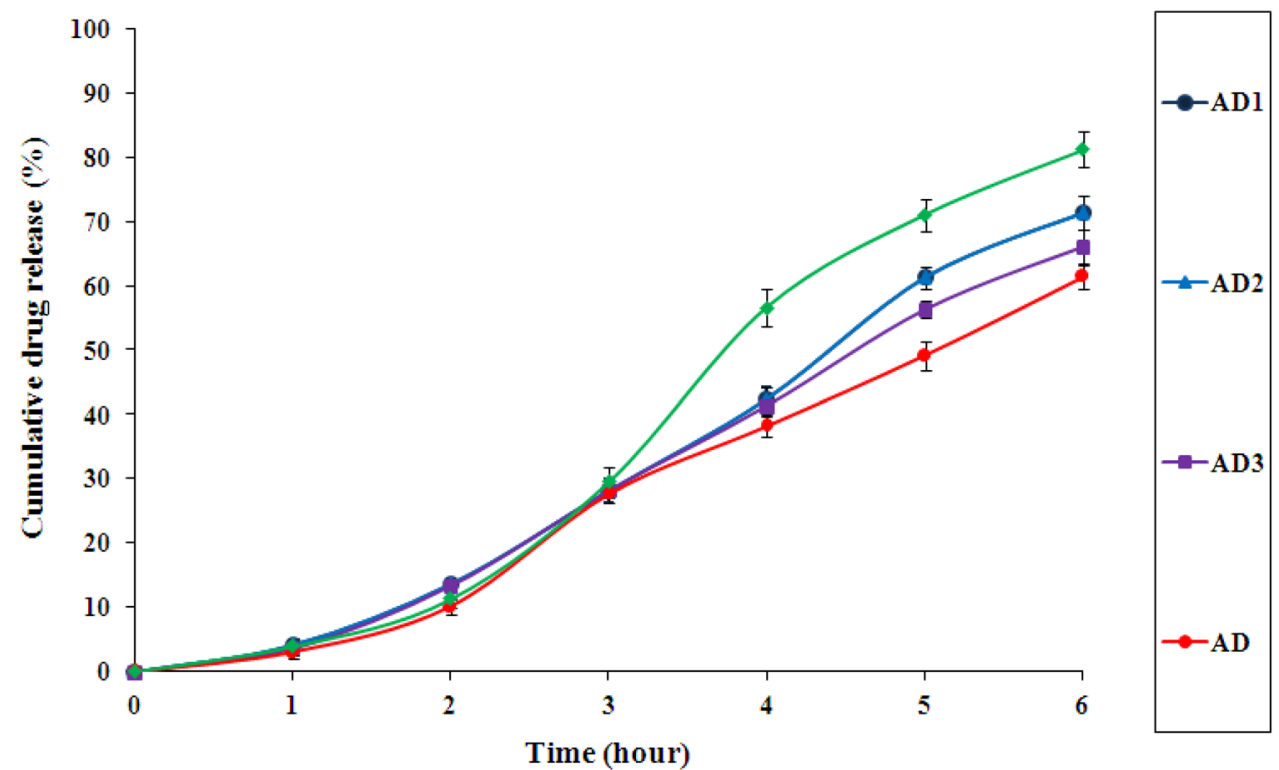

\begin{tabular}{lllll}
\hline $\begin{array}{l}\text { Formulation } \\
\text { code }\end{array}$ & \multicolumn{2}{l}{ Correlation coefficient $\left(\mathrm{R}^{2}\right)$} & \\
\cline { 2 - 5 } & Zero-order model & First-order model & Higuchi model & $\begin{array}{l}\text { Korsmeyer- } \\
\text { Peppas model }\end{array}$ \\
\hline $\mathrm{AD} 1$ & 0.9957 & 0.9103 & 0.3363 & 0.9903 \\
$\mathrm{AD2}$ & 0.9988 & 0.8732 & 0.3602 & 0.9937 \\
$\mathrm{AD3}$ & 0.9917 & 0.8666 & 0.3237 & 0.9879 \\
$\mathrm{AD}$ & 0.9548 & 0.9902 & 0.3773 & 0.9672 \\
\hline
\end{tabular}

Table 4 Curve-fitting in vitro drug release data of various aceclofeanc ( $1 \% \mathrm{w} / \mathrm{w})$ dental pastes containing extracted DG

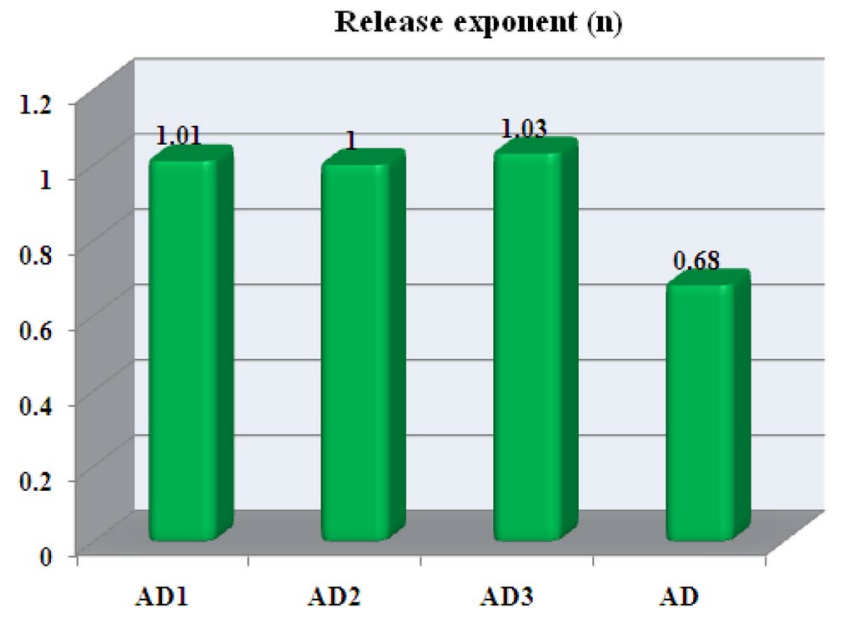

Fig. 2 Release exponent calculated from the data of in vitro aceclofeanc release from various aceclofenac $(1 \% \mathrm{w} / \mathrm{w})$ dental pastes (mean \pm standard error, $\mathrm{n}=3$ )

\subsection{Ex vivo mucoadhesion}

Ex vivo mucoadhesive assessment of these newly prepared aceclofenac $(1 \% \mathrm{w} / \mathrm{w})$ dental pastes was performed using excised porcine buccal mucosal membrane by modified physical balance. Ex vivo mucoadhesive strengths of these dental pastes were observed within the range, $32.43 \pm 0.42-159.38 \pm 6.16 \mathrm{~g}$ (Table 5). The dental pastes prepared with $2.50 \%$ of isolated DG (AD3) showed highest mucoadhesive strength $(159.38 \pm 6.16 \mathrm{~g})$ and it was also noticed that the dental pastes prepared without extracted DG (AD) demonstrated lowest mucoadhesive strength $(32.43 \pm 0.42 \mathrm{~g})$. The force of adhesion values were calculated within the range, $0.32-1.56 \mathrm{~N}$; whereas bonding strength ranged, $4027.07-19,791.36 \mathrm{~N} / \mathrm{m}^{2}$. Amongst all these newly prepared aceclofenac $(1 \% \mathrm{w} / \mathrm{w})$ dental pastes, dental paste AD3 exhibited highest force of adhesion $(1.56 \mathrm{~N})$ and bonding strength $\left(19,791.36 \mathrm{~N} / \mathrm{m}^{2}\right)$. From the results of ex vivo mucoadhesion onto excised porcine buccal mucosal membrane, it was noticed that the mucoadhesion of the dental pastes were augmented with the increment of extracted DG incorporation as mucoadhesive polymer in the dental paste-formula. As the concentration of extracted DG in the paste formula was increased, the mucoadhesivity of these prepared dental pastes was found increased. This occurrence can be because of the 
Table 5 Ex vivo mucoadhesive parameters (mucoadhesive strength, force of adhesion and bonding strength) of various aceclofeanc ( $1 \% \mathrm{w} / \mathrm{w})$ dental pastes containing extracted DG

\begin{tabular}{lllll}
\hline Mucoadhesive parameters & \multicolumn{4}{l}{ Formulation codes } \\
\cline { 2 - 5 } & AD1 & AD2 & AD3 & AD \\
\hline Mucoadhesive strength $(\mathrm{g})^{\mathrm{a}}$ & $148.57 \pm 6.77$ & $154.00 \pm 8.52$ & $159.38 \pm 6.16$ & $32.43 \pm 0.42$ \\
Force of adhesion $(\mathrm{N})^{\mathrm{a}}$ & 1.46 & 1.51 & 1.56 & 0.32 \\
Bonding strength $\left(\mathrm{N} / \mathrm{m}^{2}\right)^{\mathrm{a}}$ & 18449.01 & 19123.29 & 19791.36 & 4027.07 \\
\hline
\end{tabular}

${ }^{\mathrm{a}}$ Mean \pm standard error, $\mathrm{n}=3$ augmented viscosities of pastes with increment of the concentration of extracted DG. Various ex vivo mucoadhesive parameters of these dental pastes prepared using extracted DG were found satisfactory and hence, can be beneficial to get intimate contact with the action site during and after application. The mucoadhesive nature of these medicated dental pastes can be helpful to uphold the constant release of drugs over prolonged time period at the application site [47].

\section{Conclusion}

Dental pastes of $1 \% \mathrm{w} / \mathrm{w}$ aceclofeanc were prepared with/without using extracted DG as a plant derived natural mucoadhesive polysaccharide via conventional trituration method. The drug contents, viscosities and $\mathrm{pH}$ s of these formulated aceclofeanc dental pastes were observed within the permissible ranges. These dental pastes containing extracted DG were observed to have excellent tube extrudability and tube spreadability. The in vitro aceclofenac release from all these dental pastes was found slower sustained over a period of $6 \mathrm{~h}$, which followed zero-order kinetic model with super caseII transport mechanism. These newly prepared aceclofenac dental pastes containing extracted DG demonstrated excellent adhesion to the excised porcine buccal mucosal membrane, which may be helpful to uphold the constant release of drugs over prolonged time period at the application site. These dental pastes containing $1 \%$ $w / w$ aceclofeanc can be applied for effective management of dental pain and inflammation with local delivery in the treatment of periodontitis.

Acknowledgements The first author would like to acknowledge the University Grant Commission, New Delhi, India for providing the Maulana Azad National Fellowship for minority students.

\section{Compliance with ethical standards}

Conflict of interest The authors declare that they have no conflict of interest.

\section{References}

1. Seymour RA, Heasman PA, MacGregor IDM (1992) The pathogenesis of periodontal disease. In: MacGregor IDM (ed) Drugs, disease and the periodontium. Oxford University Press, Oxford, pp 1-10

2. Soskolone WA, Friedman M (2004) Intra-periodontal pocket drug delivery. In: Rathbone MJ (ed) Oral mucosal drug delivery, vol 74. Marcel Dekker Inc, New York, pp 359-379

3. Pataquiva Mateus AY, Ferraz MP, Monteiro FJ (2007) Nanohydroxyapatite microspheres for periodontitis treatment: preparation and cytotoxicity studies. Eur Cells Mater 14:85

4. Lindhe J, Haffajee AD, Socransky SS (1983) Progression of periodontal disease in adult subjects in absence of periodontal therapy. J Clin Periodontal 10:433-442

5. Pihlstrom BL, Michalowicz BS, Johnson NW (2005) Periodontal diseases. Lancet 366:1809-1820

6. Ahmed MG, Harish NM, Charyulu RN, Prabhu P (2009) Formulation of chitosan-based ciprofloxacin and diclofenac film for periodontitis therapy. Trop J Pharm Res 8:33-41

7. Barat R, Srinatha A, Pandit JK, Ridhurkar A, Balasubramaniam J, Mittal N, Mishra DN (2006) Niridazole biodegradable inserts for local long term treatment of periodontitis: possible new life for an orphan drug. Drug Deliv 13:365-373

8. Joshi D, Garg T, Goyal AK, Rath G (2016) Advanced drug delivery approaches against periodontitis. Drug Deliv 23(2):363-377

9. Rang HP, Dale MM, Ritter JM (1999) Pharmacology, 4th edn. Churchill Livingstone, London

10. Williams RC, Jeffcoat MK, Howell TH, Rolla A, Stubbs D, Teoh KW, Reddy MS, Goldhaber P (1989) Altering the progression of human bone loss with non-steriodal anti-inflammatory drug flurbiprofen. J Periodont 60:485-490

11. Patel KT, Patel MV (2013) Formulation and evaluation of medicated dental pastes for treatment of periodontitis. Int J Pharm Innov 3:5-8

12. Nayak AK, Malakar J, Pal D, Hasnain MS, Beg S (2017) Soluble starch-blended $\mathrm{Ca}^{2+}-\mathrm{Zn}^{2+}$-alginate composites-based microparticles of aceclofenac: formulation development and in vitro characterization. Future J Pharm Sci 4:63-70. https:// doi.org/10.1016/j.fjps.2017.10.001

13. Nayak AK, Pal D, Hasnain MS (2013) Development, optimization and in vitro-in vivo evaluation of pioglitazone-loaded jackfruit seed starch-alginate beads. Curr Drug Deliv 10(5):608-619

14. Sinha P, Ubaidulla U, Nayak AK, Hasnain MS, Rama B (2015) Alginate-okra gum blend beads of diclofenac sodium from aqueous template using ZnSO4 as a cross-linker. Int J Biol Macromol 79:555-563. https://doi.org/10.1016/j.ijbiomac.2015.04.067

15. Nayak AK, Khatua S, Hasnain MS, Sen KK (2011) Development of diclofenac sodium-loaded alginate-PVP K 30 microbeads using central composite design. Daru 19:5 
16. Nayak AK, Pal D, Pradhan J, Hasnain MS (2013) Fenugreek seed mucilage-alginate mucoadhesive of metformin $\mathrm{HCl}$ : design, optimization and evaluation. Int J Biol Macromol 54:144-154

17. Nayak AK, Ara TJ, Hasnain MS, Hoda N (2018) Okra gum-alginate composites for controlled drug releasing delivery. In: Inamuddin $M$ (ed) Applications of nanocomposite materials in drug delivery. Elsevier, Cambridge, pp 761-785

18. Milivojevic M, Pajic-Lijakovic I, Bugarski B, Nayak AK, Hasnain MS (2019) Gellan gum in drug delivery applications. In: Hasnain MS, Nayak AK (eds) Natural polysaccharides in drug delivery and biomedical applications. Elsevier, Cambridge, pp 145-186

19. Hasnain SMM, Hasnain MS, Nayak AK (2019) Natural polysaccharides: sources and extraction methodologies. In: Hasnain MS, Nayak AK (eds) Natural polysaccharides in drug delivery and biomedical applications. Elsevier, Cambridge, pp 1-14

20. Nayak AK, Ahmed SA, Tabish M, Hasnain MS (2019) Natural polysaccharides in tissue engineering applications. In: Hasnain MS, Nayak AK (eds) Natural polysaccharides in drug delivery and biomedical applications. Elsevier, Cambridge, pp 531-548

21. Bera H, Abbasi YF, Hasnain MS, Nayak AK (2019) Sterculia gum in drug delivery applications. In: Hasnain MS, Nayak AK (eds) Natural polysaccharides in drug delivery and biomedical applications. Elsevier, Cambridge, pp 223-247

22. Dey S, Nandy BC, De JN, Hasnain MS, Nayak AK (2019) Tamarind gum in drug delivery applications. In: Hasnain MS, Nayak AK (eds) Natural polysaccharides in drug delivery and biomedical applications. Elsevier, Cambridge, pp 285-306

23. Samanta A, De A, Hasnain MS, Bera H, Nayak AK (2019) Gum odina as pharmaceutical excipient. In: Hasnain MS, Nayak AK (eds) Natural polysaccharides in drug delivery and biomedical applications. Elsevier, Cambridge, pp 327-337

24. Nayak AK, Ansari MT, Sami F, Bera H, Hasnain MS (2019) Cashew gum in drug delivery applications. In: Hasnain MS, Nayak AK (eds) Natural polysaccharides in drug delivery and biomedical applications. Elsevier, Cambridge, pp 263-283

25. Ansari MT, Sami F, Majeed S, Hasnain MS, Badgujar VB (2019) Design and evaluation of topical herbal antifungal stick containing extracts of Rhinacanthus nasutus. J Herb, Med, p 100290

26. Hasnain MS, Rishishwar P, Rishishwar S, Ali S, Nayak AK (2018) Isolation and characterization of Linum usitatisimum polysaccharide to prepare mucoadhesive beads of diclofenac sodium. Int J Biol Macromol 116:162-172

27. Hasnain MS, Rishishwar P, Rishishwar S, Ali S, Nayak AK (2018) Extraction and characterization of cashew tree (Anacardium occidentale) gum; use in aceclofenac dental pastes. Int J Biol Macromol 116:1074-1081

28. Nayak AK, Kalia S, Hasnain MS (2013) Optimization of aceclofenac-loaded pectinate-poly (vinyl pyrrolidone) beads by response surface methodology. Int J Biol Macromol 62:194-202

29. Jana S, Ali SA, Nayak AK, Sen KK, Basu SK (2014) Development and optimization of topical gel containing aceclofenaccrospovidone solid dispersion by "Quality by Design" approach. Chem Eng Res Des 92:2095-2105

30. Jana S, Saha A, Nayak AK, Sen KK, Basu SK (2013) Aceclofenacloaded chitosan-tamarind seed polysaccharide interpenetrating polymeric network microparticles. Colloids Surf B Biointerface 105:303-309

31. Malakar J, Nayak AK, Das A (2013) Modified starch (cationized)alginate beads containing aceclofenac: formulation optimization using central composite design. Starch Stärke 65:603-612

32. Guru PR, Bera H, Das MP, Hasnain MS, Nayak AK (2017) Aceclofenac-loaded Plantago ovata F. husk mucilage- $\mathrm{Zn}+2$-pectinate controlled-release matrices. Starch Stärke 70(3-4):1700136. https://doi.org/10.1002/star.201700136
33. Jyothsna K, Deshpande N, Vijayalakshmi G (2011) Efficacy and safety of diclofenac sodium and aceclofenac in controlling post extraction dental pain: a randomised open label comparative study. J Pharmacol Toxicol 6:41-47

34. Ketousetuo K, Bandyopadhyay AK (2007) Development of oxytocin nasal gel using natural mucoadhesive agent obtained from the fruits of Dellinia indica L. Sci Asia 33:57-60

35. Sharma HK, Lahkar S, Nath LK (2013) Extraction, characterisation and compatibility study of polysaccharides from Dillenia indica and Abelmoschus esculentus with metformin hydrochloride for development of drug delivery system. Int Pharm Tech Res 5:275-283

36. Sahu BP, Sharma HK, Das MK (2011) Development and evaluation of a mucoadhesive nasal gel of felodipine prepared with mucoadhesive substance of Dillenia indica L. Asian J Pharm Sci 5:175-187

37. Sharma HK, Pradhan SP, Sarangi B (2009) Preparation and in vitro evaluation of mucoadhesive microbeads containing timolol maleate using mucoadhesive substances of Dellinia india L. Arch Pharm Res 1:181-188

38. Sharma HK, Pradhan SP, Sarangi B (2010) Enteric controlled release pantoprazole loaded microbeads using natural mucoadhesive substance from Dillenia indica L. Int J Pharm Technol Res 2:542-551

39. Malakar J, Basu A, Nayak AK (2014) Candesartan cilexetil microemulsions for transdermal delivery: formulation, in vitro skin permeation and stability assessment. Curr Drug Deliv 11:313-321

40. Hasnain MS, Rishishwar P, Ali S (2017) Use of cashew bark exudate gum in the preparation of $4 \%$ lidocaine $\mathrm{HCL}$ topical gels. Int J Pharm Pharm Sci 9(8):146-150

41. Hasnain MS, Rishishwar P, Ali S (2017) Floating-bioadhesive matrix tablets of hydralazine $\mathrm{HCL}$ made of cashew gum and HPMC K4M. Int J Pharm Pharm Sci 9(7):124-129

42. Das B, Nayak AK, Nanda U (2013) Topical gels of lidocaine $\mathrm{HCl}$ using cashew gum and Carbopol 940: preparation and in vitro skin permeation. Int J Biol Macromol 62:514-517

43. Das B, Sen SO, Maji R, Nayak AK, Sen KK (2017) Transferosomal gel for transdermal delivery of risperidone. J Drug Deliv Sci Technol 38:59-71

44. Malakar J, Sen SO, Nayak AK, Sen KK (2011) Development and evaluation of microemulsion for transdermal delivery of insulin. ISRN Pharm Article ID 780150

45. Malakar J, Nayak AK, Basu A (2012). Ondansetron HCl microemulsions for transdermal delivery: formulation and in vitro skin permeation. ISRN Pharm Article ID 428396

46. Malakar J, Sen SO, Nayak AK, Sen KK (2012) Formulation, optimization and evaluation of transferosomal gel for transdermal insulin delivery. Saudi Pharm J 20:355-363

47. Ratha Adhikari SN, Nayak BS, Nayak AK, Mohanty B (2010) Formulation and evaluation of buccal patches for delivery of atenoIol. AAPS Pharm Sci Technol 11(3):1038-1044

48. Gupta A, Garg S, Khar RK (1992) Measurement of bioadhesion strength of muco-adhesive buccal tablet: design of an in vitro assembly. Indian Drugs 30:152-155

49. Patel VM, Prajapati BG, Patel MM (2007) Design and characterization of chitosan-containing mucoadhesive buccal patches of propranolol hydrochloride. Acta Pharm 57:61-72

Publisher's Note Springer Nature remains neutral with regard to jurisdictional claims in published maps and institutional affiliations. 